\title{
Analysis on Hover Control Performance of T- and Cross-Shaped Tail Fin of X-Wing Single-Bar Biplane Flapping Wing
}

\author{
Pingxia Zhang $\mathbb{D}^{1}{ }^{1}$ Junru Zhu, ${ }^{2}$ and Yongqiang Zhu $\mathbb{D}^{1}$ \\ ${ }^{1}$ School of Mechanical and Automotive Engineering, Qingdao University of Technology, Qingdao 266520, China \\ ${ }^{2}$ Pegasus California School, Qingdao 266105, China \\ Correspondence should be addressed to Yongqiang Zhu; yongqiangzhu@163.com
}

Received 3 April 2020; Revised 22 May 2020; Accepted 2 June 2020; Published 21 July 2020

Academic Editor: Weitian Wang

Copyright ( 2020 Pingxia Zhang et al. This is an open access article distributed under the Creative Commons Attribution License, which permits unrestricted use, distribution, and reproduction in any medium, provided the original work is properly cited.

The current flapping wing adopts T-shaped or cross-shaped tail fin to adjust its flight posture. However, how the tail fin will affect the hover control is not very clear. So, the effects of the two types of tail on flight will be analyzed and compared by actual flight tests in this paper. Firstly, we proposed a new X-wing single-bar biplane flapping-wing mechanism with two pairs of wings. Thereafter, the overall structure, gearbox structure, tail, frame, and control system of the flapping wing were designed and analyzed. Secondly, the control mechanism of hover is analyzed to describe the effect of two-tail fin on posture control. Thirdly, the Beetle was used as the control unit to achieve a controllable flight of flapping wing. The MPU6050 electronic gyroscope was used to monitor the drone's posture in real time, and the Bluetooth BLE4.0 wireless communication module was used to receive remote control instructions. At last, to verify the flight effect, two actual flapping wings were fabricated and flight experiments were conducted. The experiments show that the cross-shaped tail fin has a better controllable performance than the T-shaped tail fin. The flapping wing has a high lift-to-mass ratio and good maneuverability. The designed control system can achieve the controllable flight of the flapping wing.

\section{Introduction}

Flying creatures of nature all use a flapping wing to fly. They flap wings and change the angle and shape of their wing and tail fin, to create lift and propulsion, and change the direction of flight and flight mode. By doing these, they can easily realize the rapid and flexible flight movements [1], such as flying, gliding, and hovering. Then, they can have very high mobility and flexibility of the flight and realize a high structural pattern of a pair of wings with multiple functions. Especially, hummingbirds have good hovering flight performance, as shown in Figure 1. This inspired us to design a small, smart, and flexible drone.

An ornithopter is a drone whose wings flutter up and down like birds or insects. Most researches contribute and innovate in the following aspects: wing shape analysis [2, 3], the aerodynamics of flapping wing [4-7], power extraction performance of semiactive flapping airfoils [8], mechanism [9-11], different actuation mechanisms, hybrid actuation mechanisms [12], electrical motor-driven method, mechanical transmissiondriven method, and "artificial muscle" material-driven method [13].

At present, the flapping-wing drone that can successfully fly can be divided into forward flight and hover flight from the flight function and can be divided into two categories from the presence or absence of the tail: the tailless (Figure 2) and the tailed. The tailed flapping-wing drone can be divided into three types: horizontal tail fin (Figures 3(e), 3(g), 3(h), and 3(k)), T-shaped tail fin (Figures 3(a), 3(b), 3(f), 3(i), 3(j), and 3(l)), and cross-shaped tail fin (Figures 3(c) and 3(d)). These research studies provide great contribution and innovation for making flapping wing to successfully fly. If the tail structure is too complicated, it will increase the weight of the tail and make the drone difficult to fly. So, the tail of the actual flapping-wing drone will not be too complicated, and for easy control, most of the flapping-wing drones use Tand cross-shaped tail fin. 


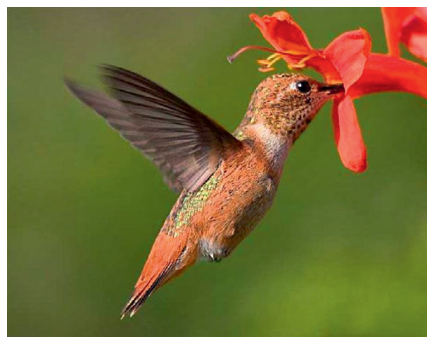

FIGURE 1: Hummingbirds can hover easily by changing the angle and shape of their wings and tail fin.

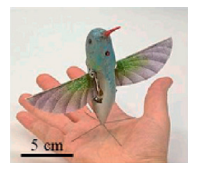

(a)

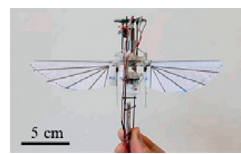

(g)

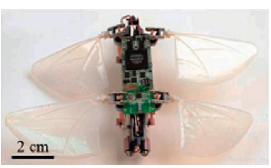

(b)

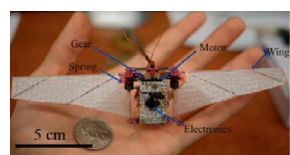

(h)

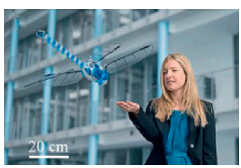

(c)

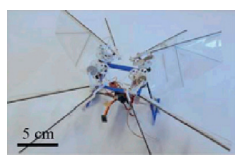

(i)

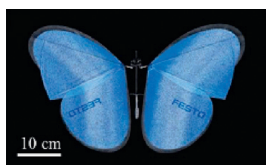

(d)

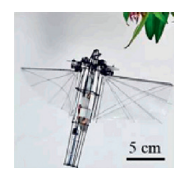

(j)

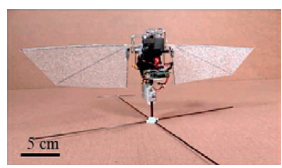

(e)

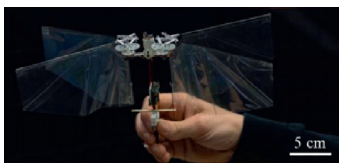

$(\mathrm{k})$

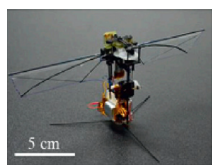

(f)

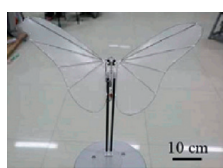

(1)

FIgURE 2: Motor-driven insect-inspired tailless FWMAVs capable of free controlled flying. (a) Nano Hummingbird developed by AeroVironment Inc. [14]. (b) TechJect Dragonfly developed by TechJect Inc. [15]. (c) BionicOpter developed by Festo AG \& Co. KG [16]. (d) eMotionButterflies developed by Festo AG \& Co. KG [17]. (e) Robotic Hummingbird developed by Texas A\&M University [18]. (f) KUBeetle developed by Konkuk University [19]. (g) Colibri robot developed by the Université Libre de Bruxelles [20]. (h) Robotic Hummingbird developed by Purdue University [21]. (i) Quad-thopter developed by Delft University of Technology [22]. (j) NUS-Robobird developed by the National University of Singapore [23]. (k) DelFly Nimble developed by the Delft University of Technology [24]. (l) Butterfly-type ornithopter developed by Beihang University [25].

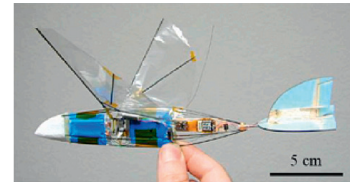

(a)

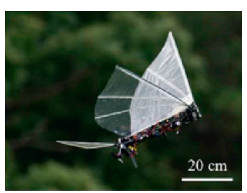

(e)

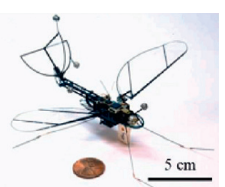

(i)

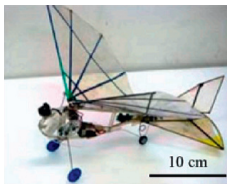

(b)

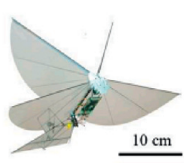

(f)

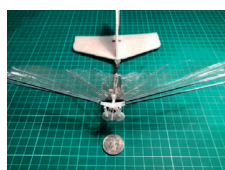

(j)

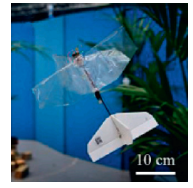

(c)

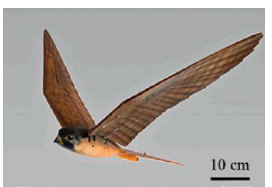

(g)

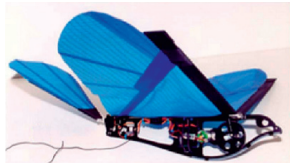

$(\mathrm{k})$

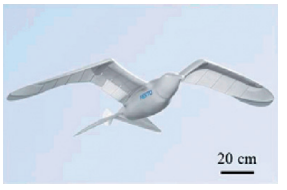

(d)

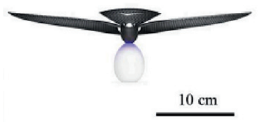

(h)

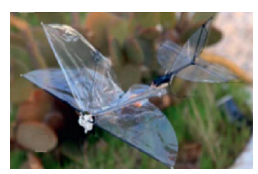

(l)

Figure 3: Examples of existing bird-inspired tailed FWAVs. (a) Microbat from AeroVironment Inc. [26]. (b) 32 g ornithopter from Konkuk University [27]. (c) DelFly Explorer from the Delft University of Technology [28]. (d) SmartBird from Festo AG \& Co. KG [29]. (e). Robo Raven V from the University of Maryland [30]. (f) H2Bird ornithopter from the University of California, Berkeley [31]. (g) Robird from Clear Flight Solutions and the University of Twente [32]. (h) BionicBird from http://bionicbird.com. (i) $3.2 \mathrm{~g}$ flapping-wing platform from Harvard University [33]. (j) NAV from the American University of Sharjah [34]. (k) Slow Hawk 2 from Kinkade R/C. (l) Butterfly's spy drone from Israel Aircraft Industries (IAI) [35]. 
For ornithopter, it is more difficult to hover like a hummingbird, since its aerodynamic $[36,37]$ and mechanism [38] are more complex. Moreover, it should produce more drag force to balance gravity and be controlled better than flying forwards only [39-42]. And the hovering flapping wing has more flying potential. Therefore, many researchers carry out stability analysis of near-hovering [43] or hovering $[44,45]$ and use various control strategies, such as adaptive control [46], passive stability enhancement [47], Spiking Neural Network (SNN) control [48], sliding-mode approach [49, 50], and adaptive feedforward schemes [51]. However, these make the ornithopter adopt more powerful control unit and more expensive.

Moreover, at present, the ornithopter adopts mostly the structure of imitating birds' wings [52] — the whole ornithopter only has one pair of wings. Due to the great difference in the freedom and flexibility between the ornithopter and birds' wings, the lift of the ornithopter will decrease when the wings are flapped upwards. Therefore, special structures need to be designed to compensate, resulting in complex wing structures [53-55] and increased weight of the ornithopter.

In addition, few papers have analyzed the influence of the tail fin shape on the hovering effect.

Therefore, in this paper, we designed a new X-wing single-bar biplane flapping-wing flight vehicle to imitate the hummingbird vertical hovering flight. Then, we analyzed and compared hover performance of two kinds of tail fin.

The remaining sections of this article are organized as follows: in the second section, the structure of the X-wing flapping-wing drone is designed. It can further enhance flight thrust through the synchronization of two pairs of wings beat-up and squeeze the air vortex flow. Therefore, it can both generate thrust while flapping up and down. In the third section, the control mechanism of the T-shaped and cross-shaped tail fin is analyzed. Then, the control variables and implementation are proposed. In the fourth section, control circuit and software modules are designed. The fly control system can get the gyroscope data in the flapping wing and receive the operator's command via Bluetooth. In the fifth section, hovering experiments are conducted and analyzed to verify the flight performance. Finally, conclusions of this article are presented in the sixth section.

\section{Structure Design of X-Shaped Flapping- Wing Drone}

Many flapping wings use double-bar wing (Figure 4) [56]. Since the left wing and right wing do not use the same bar, there should be other components to connect the left bar and right bar. This will increase the weight. We designed a new single-bar wing (Figure 5). The wings were improved from double-bar to single-bar, simplifying the structure and enhancing the strength. The two pairs of wings of the new $\mathrm{X}$-wing ornithopter are arranged in an X-shaped cross using two single-bar wings, with a total of four wings. By doing this, we can simplify the flapping support structure.

The ornithopter is composed of gearbox, tail fin, body frame, and control system, as shown in Figure 6.

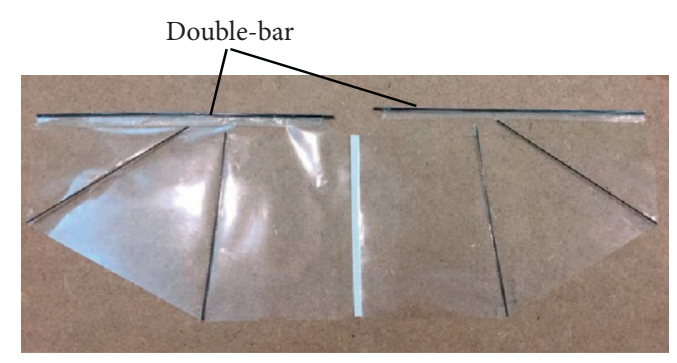

Figure 4: Double-bar wing.

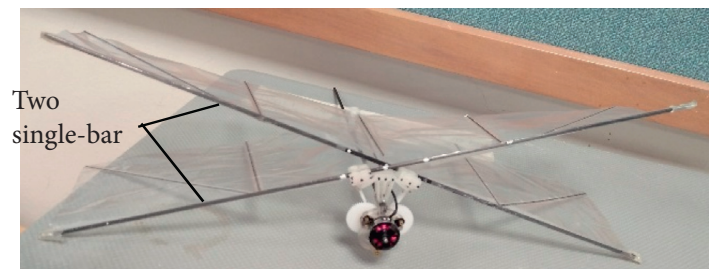

Figure 5: Single-bar wing.

2.1. Gearbox. Figure 7 illustrates the gearbox structure composition. The gearbox is an important mechanism to reduce the speed of the motor, increase the torque of the motor, and convert the rotary motion of the motor into the reciprocating flapping motion of the wings. When the brushless motor rotates, it drives the swing arm gear to rotate via the two-stage reduction of the motor gear and the middle gear. The two swing arm gears mesh with each other to realize the transmission of power from the right swing arm gear to the left. The swing arm gear drives the eccentric cam to rotate. The eccentric cam drives the tie rod to turn the rotary motion into a reciprocating motion of the tie rod. The tie rod then drives the elastic support on the wings to swing up and down through the small lifting lugs to achieve flapping motion. The elastic support and the body frame are connected through an elastic hinge to achieve both rotation restraint and certain energy recovery. The entire gearbox system is fixed on the body frame through a gearbox plate.

In this way, the gearbox plate, the eccentric cam, the tie rod, and the elastic support constitute a crank rocker mechanism, as shown in Figure 8. By optimizing the size of each component, on the premise that the optimal working range (speed, torque) of the motor and the flapping frequency of the wings are met, the angle range of the elastic support movement can be controlled. When the amplitude of the elastic support is $54.32^{\circ}$, the angle between the upper and lower wings is maximized when the wings are deployed. It reaches $111.5^{\circ}$. The minimum angle between the upper and lower wings is $2.86^{\circ}$ when the wings are folded together. They both meet the requirements of wing motion amplitude. Figure 8 shows the curve of the wing angle with time when the wings are flapped up and down after optimization.

2.2. Tail Fin. Figure 6 illustrates the tail fin structure composition. The tail fin is an important part of controlling the flying pose of the flapping-wing drone. Its main function is to control the angle of the rudder wing and the elevator wing 


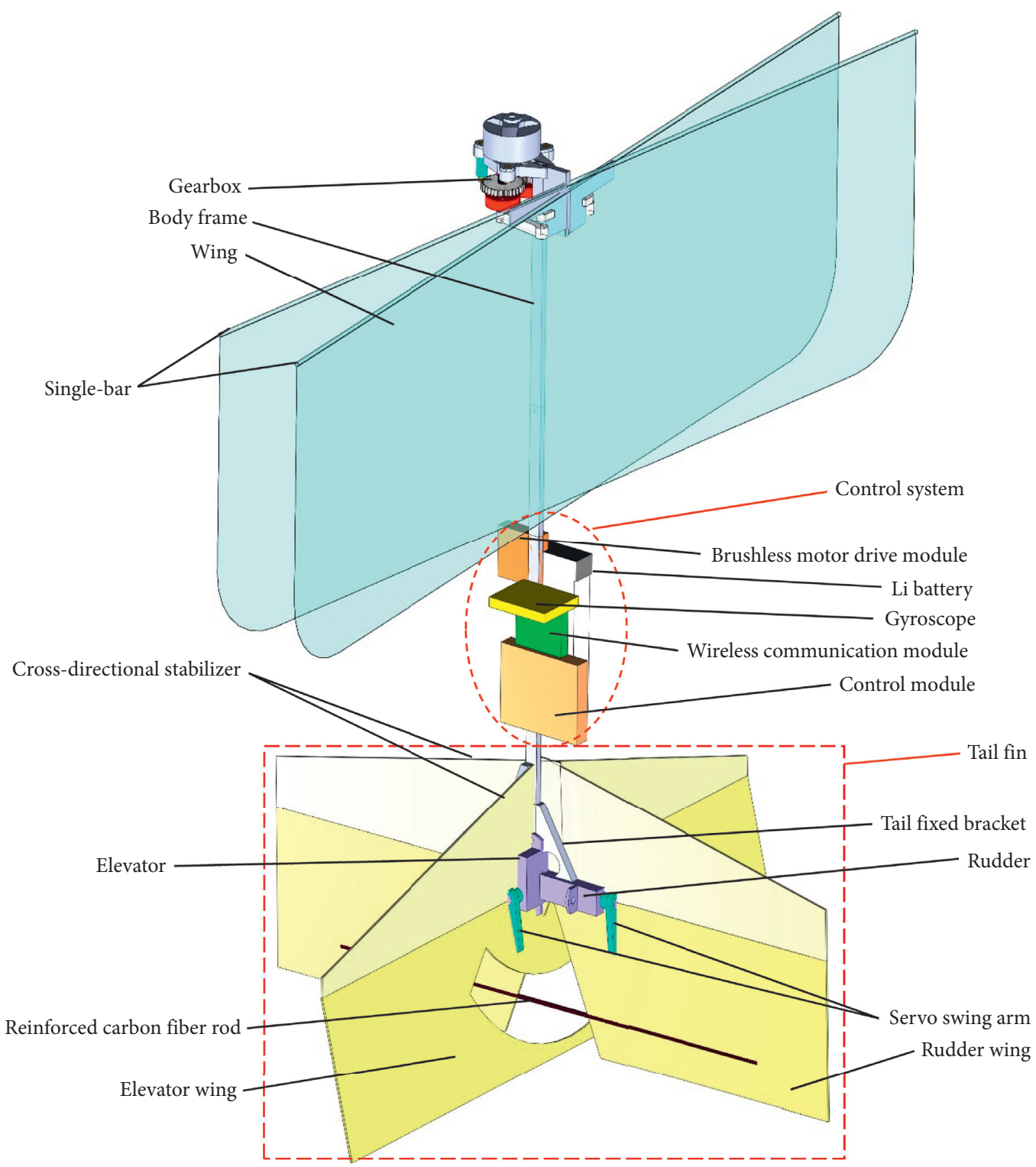

FIgURE 6: The overall structure of the X-shaped ornithopter.

through the servo motor and then change the pitching and leftright flight direction of the flapping-wing drone. The tail fin is mainly composed of a tail fixed bracket, a cross-directional stabilizer, a rudder, an elevator, a rudder wing, an elevator wing, a rudder swing arm, and a reinforced carbon fiber rod. When the flapping-wing machine needs to change the direction of the pitching motion, the rudder (or elevator) will drive the swing arm. Since the swing arm and the rudder wing (or the elevator wing) are fixed together, the swing arm of the servo will drive the rudder wing (or the elevator wing) to rotate around the connection axle between the stabilizer wing and the rudder wing (or the elevator wing). Then the drone will change the direction of the airflow flowing through the tail fin and realize the change of the direction of the flapping-wing drone.

2.3. Body Frame. The body frame is a rod-shaped structure with a rectangular cross section, and its main function is to fix the entire structural assembly of the flapping-wing drone.
Since carbon fiber has the lightest mass among the materials that can be selected with the same strength and stiffness, the carbon fiber material is selected as the body material.

\section{Control Theory}

3.1. Body Dynamics. The positive directions of the coordinates are displayed in Figure 9. The $x$-axis is perpendicular to the flapping-wing surface and points forward, the $y$-axis is pointing to the left of the flapping-wing drone, and the $z$-axis is vertically upward. The dynamics of the ornithopter can be described, under rigid body assumption, by Newton-Euler motion equations. Similar to a drone, we obtain 12 ordinary differential equations with 12 unknown coordinates: velocity $(u, v, w)$, angular velocity $(p, q, r)$, position $(x, y, z)$, and orientation expressed by Roll-Pitch-Yaw angles $(\varphi, \theta, \delta)$ by omitting the equations for position and heading (yaw) [20, 57-59]. 


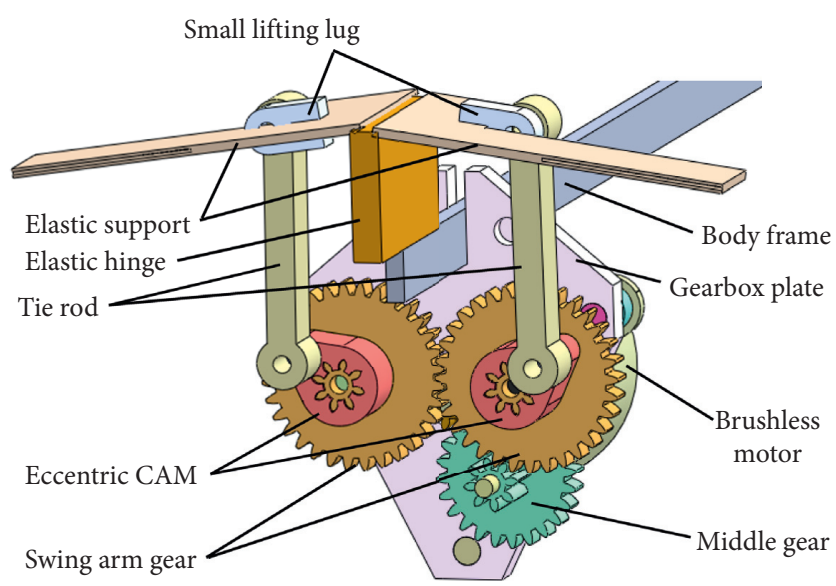

(a)

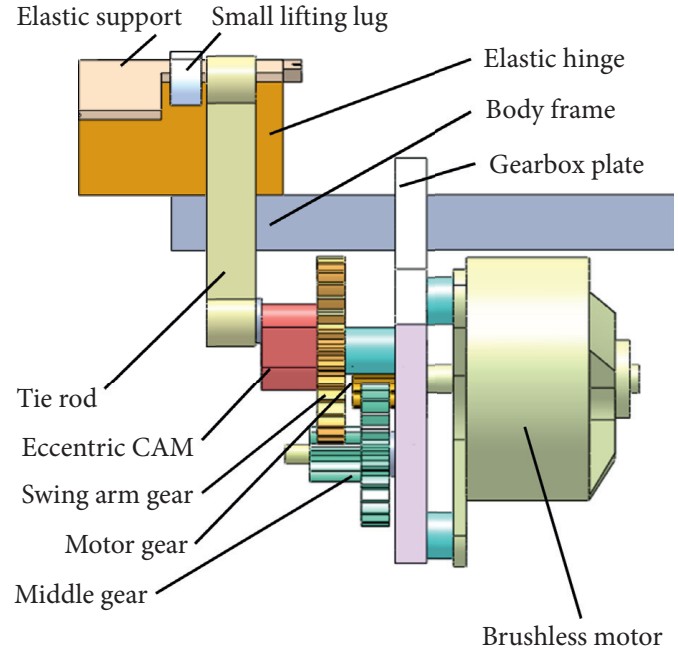

(b)

FIGURE 7: Gearbox structure composition. (a) Gearbox isometric view. (b) Gearbox side view.

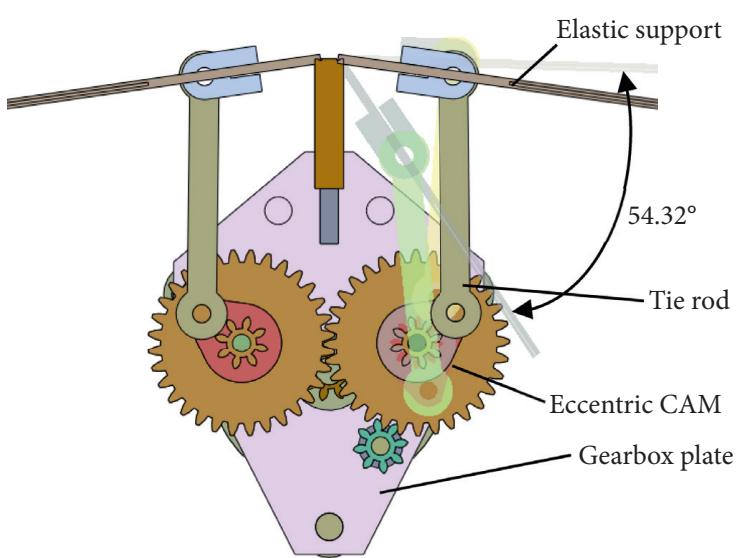

(a)

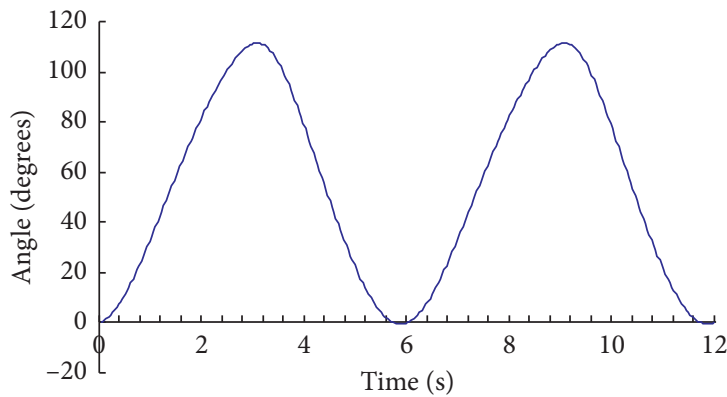

(b)

FIgURE 8: (a) Crank rocker mechanism and (b) the curve of the angle between the upper and lower wings with time when the wings are flapped up and down after optimization.

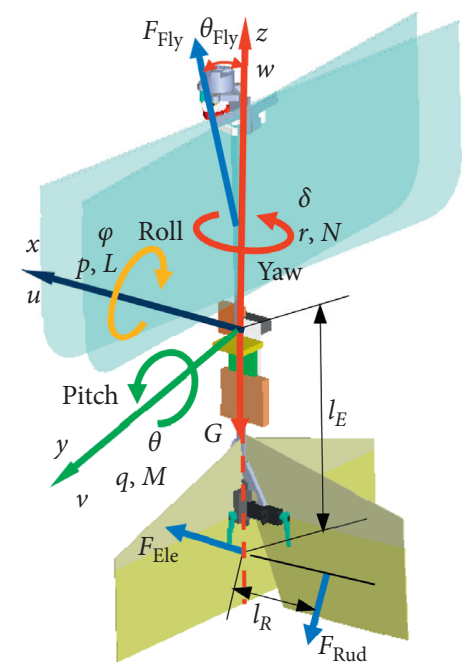

(a)

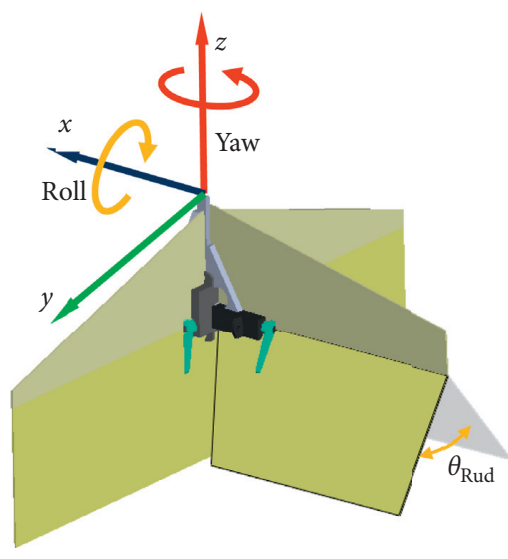

(b)

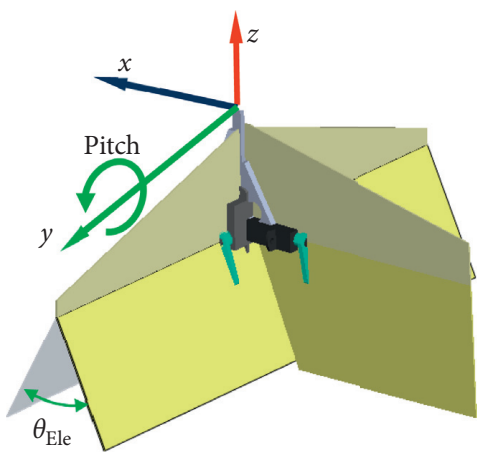

Figure 9: Continued.

(c) 


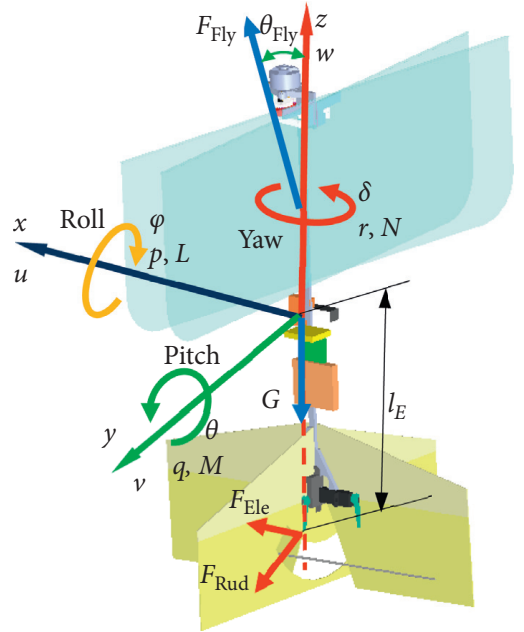

(d)

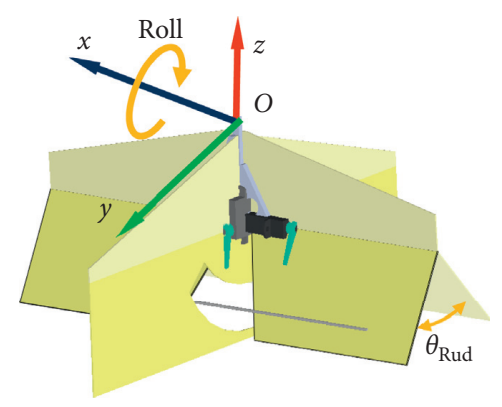

(e)

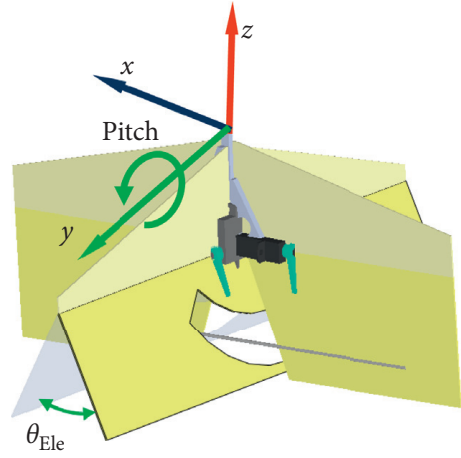

(f)

FiguRE 9: The positive directions of the coordinates and control mechanism: (a) dynamic analysis of T-shaped tail fin; (b) roll-control and yaw-control by moving the rudder wing; (c) pitch-control by moving the elevator wing; (d) dynamic analysis of cross-shaped tail fin; (e) rollcontrol by moving the rudder wing; and (f) pitch-control by moving the elevator wing.

The system is reduced to 8 equations:

$$
\begin{aligned}
\dot{u} & =-(w p-v r)+\frac{X}{m}+g \sin \theta, \\
\dot{v} & =-(u r-w p)+\frac{Y}{m}-g \cos \theta \sin \varphi, \\
\dot{w} & =-(v p-u q)+\frac{Z}{m}-g \cos \theta \cos \varphi, \\
I_{x x} \dot{p} & =\left(I_{y y}-I_{z z}\right) q r+I_{x z}(\dot{r}+p q)+L, \\
I_{y y} \dot{q} & =\left(I_{z z}-I_{x x}\right) p r+I_{x z}\left(r^{2}-p^{2}\right)+M, \\
I_{z z} \dot{r} & =\left(I_{x x}-I_{y y}\right) p q+I_{x z}(\dot{p}+q r)+N, \\
\dot{\varphi} & =p+q \sin \varphi \tan \theta+r \cos \varphi \tan \theta, \\
\dot{\theta} & =q \cos \varphi-r \sin \varphi .
\end{aligned}
$$

Here, $m$ is the body mass, and $I_{x x}, I_{y y}, I_{z z}$, and $I_{x z}$ are both nonzero moments and product of inertia in body frame (products $I_{x y}$ and $I_{y z}$ are both zero due to body symmetry). Aerodynamic forces and moments are represented by vectors $(X, Y, Z)$ and $(L, M, N)$, respectively [60-62].

The wing forces and tail fin forces are transformed into the body frame as follows:

$$
\begin{aligned}
X & =F_{\text {Fly }} \sin \theta_{\text {Fly } x z}+F_{\text {Ele }}, \\
Y & =F_{\text {Fly }} \sin \theta_{\text {Fly } y z}+F_{\text {Rud }}, \\
Z & =F_{\text {Fly }} \cos \theta_{\text {Fly }}-G, \\
L & =F_{\text {Rud }} l_{E} \\
M & =-F_{\text {Ele }} l_{E}, \\
F_{\text {Rud }} & =\frac{1}{2} \rho V^{2} S_{W R} C_{Y \theta_{\text {Rud }}} \theta_{\text {Rud }}, \\
F_{\text {Ele }} & =\frac{1}{2} \rho V^{2} S_{W E} C_{Y \theta_{\text {Ele }}} \theta_{\text {Ele }} .
\end{aligned}
$$

Here, $F_{\text {Fly }}$ is the drag force produced by flapping wings, $\theta_{\text {Fly }}$ is the angle between $F_{\text {Fly }}$ and $z$-axis, $\theta_{\text {Fly } x z}$ and $\theta_{\text {Fly } y z}$ are the projection of angle $\theta_{\mathrm{Fly}}$ on $x-z$ plane and $y-z$ plane, respectively, $F_{\text {Rud }}$ and $F_{\text {Ele }}$ are the rudder force and elevator force produced by rudder wings and elevator wings, respectively, $l_{E}$ is the projection of the distance the tail fin and the center of gravity of the ornithopter onto the $z$-axis, $\rho$ is air density, $V$ is airflow velocity, $S_{W R}$ and $S_{W E}$ are the area of the rudder wings and elevator wings, respectively, $C_{Y \theta_{\text {Rud }}}$ and $C_{Y \theta_{\mathrm{Ele}}}$ are the rudder lateral force derivative and the elevator longitudinal force derivative, and $\theta_{\text {Rud }}$ and $\theta_{\text {Ele }}$ are the rudder and elevator rotation angles, respectively.

Since the rudder wing of the T-shaped tail fin is not plane-symmetrical about $y$ - $z$ surface, the flapping wing of T-shaped tail fin has one more $N$ torque than the crossshaped tail fin: 


$$
N=-F_{\text {Rud }} l_{R} .
$$

Here, $l_{R}$ is the projection of the distance between $F_{\text {Rud }}$ and the center of gravity of the ornithopter onto the $y$-axis.

So, $N$ torque will cause hovering flapping-wing extra yaw movement of the T-shaped tail fin. It should be compensated by appropriate control mechanism. Hence, the flapping wing of the cross-shaped tail fin will hover in a more controllable manner than the T-shaped tail fin, because its rudder wing is plane-symmetrical about $y-z$ surface.

From these equations, we can see that the flapping-wing posture can be controlled by the rudder rotation angles $\theta_{\text {Rud }}$ and elevator rotation angles $\theta_{\text {Ele. }}$.

Figure 9 also shows the control mechanism integrated in our present flapping wing; when the rudder wing is moved by a rudder servo as shown in Figures 9 (b) and 9(e), the ornithopter will create a rolling moment to rotate about the $x$-axis. The T-shaped ornithopter will also create a yawing moment to rotate about the $z$-axis. Similarly, when the elevator wing is moved by an elevator servo as shown in Figures 9(c) and 9(f), the ornithopter will create a pitching moment to rotate about the $y$-axis. The two degrees of control allow us to effectively control the ornithopter.

Therefore, if we want the ornithopter to have a good hover flight performance, the tail fin must be symmetrical about the longitudinal axis ( $z$-axis) of the ornithopter.

3.2. Control Strategy. The servo output off-angle position is

$$
\begin{aligned}
P_{\text {out }} & =K_{p} \Delta_{A}+K_{d} \frac{\mathrm{d} \Delta_{A}}{\mathrm{~d} t}+K_{i} \int \Delta_{A} \mathrm{~d} t, \\
\Delta_{A} & =T_{A}-A_{c} .
\end{aligned}
$$

Here, $K_{p}, K_{d}$, and $K_{i}$ are the parameters of the PID, respectively; $T_{A}$ and $A c t_{A}$ are the target posture angle from a remote control and actual posture angle from a gyroscope.

The gyroscope can output precise angle velocity, so it is unnecessary to derive $\Delta_{A}$ in single-chip microcomputer; then,

$$
\frac{\mathrm{d} \Delta_{A}}{\mathrm{~d} t}=-\frac{\mathrm{d} A c t_{A}}{\mathrm{~d} t}=-A c t_{\omega} .
$$

Here, $A c t_{\omega}$ are actual posture angle velocity from gyroscope.

So, the servo output off-angle position changes to

$$
P_{\text {out }}=K_{p} \Delta_{A}-K_{d} A c t_{\omega}+K_{i} \int \Delta_{A} \mathrm{~d} t .
$$

By doing this, the requirements for the control system can be decreased. It can improve PID strategy speed. And the hovering can be controlled better.

Since the servo position is 90 when the flapping wing in hover balance, the new servo position after PID being controlled is

$$
P=90+P_{\text {out }} .
$$

According to the signal from a gyroscope and remote control, we can calculate the new rudder servo position and elevator servo position, respectively. By using this strategy, we can control the ornithopter hovering. Currently, there is no control over the yaw axis, which is passively stable by adjusting the fixed angle of two elevator wings manually. Because if we control the yaw, we will need two servos to adjust two elevator wings, respectively, not one currently. This will add weight to the flapping wing and make it fly difficultly.

\section{Control System}

4.1. Flying System Hardware. The control system mainly consists of a control module, a brushless motor drive module (BMDM), a wireless communication module, a gyroscope, and a lithium battery, as shown in Figure 6.

The control module uses Beetle single-chip microcomputer as the core control board. It can receive the target control instructions from the remote control via the Bluetooth wireless module and then generates a PWM signal based on the actual posture of the flapping-wing machine detected by a gyroscope. The PWM signal can control the servo to dynamically adjust the position of the tail fin. And Beetle also generates a PWM signal to control the speed of the brushless motor, so the flapping frequency of wings can be controlled.

Because the flapping-wing machine is very small in volume and mass, to ensure the life of the motor and meet the requirements of power-volume ratio and power-mass ratio, brushless motors and corresponding drive modules are selected here to realize the rotary drive of the flapping wing. Here, we use Hobby King AP-03 $7000 \mathrm{kV}$ Brushless Micro Motor (3.1 g). Table 1 illustrates the parameters of the brushless motor.

The wireless communication module is mainly used for receiving the instructions of the remote control and transmitting them to the control unit to realize the controllable flight of the flapping-wing drone. To save power and reduce the volume, the Bluetooth 4.0 BLE module of Cypress's CYBL series chip is selected here. It can not only save power but also simplify the wiring and programming of the main control module by using the serial communication interface protocol.

The gyroscope is used to detect the posture of the ornithopter in real time. We use the GY 901 chip. It uses an MPU6050 electronic gyroscope chip with a built-in Kalman filter algorithm. It can output various motion state parameters of the ornithopter in real time, such as angle, angular velocity, and linear velocity.

The lithium battery is $3.7 \mathrm{~V} 70 \mathrm{mAh}$, which can extend the flight time as much as possible without increasing too much weight of the drone.

The total weight of the system is $17.79 \mathrm{~g}$, and each part of the system is shown in Figure 10. The hardware circuit connection is shown in Figure 11. Figure 12 illustrates the ornithopter, control system, and remote control prototype.

4.2. Flying System Software. The system control program is mainly composed of the initialization subprogram, wireless 
TABle 1: Parameters of the $7000 \mathrm{kV}$ brushless micro motor.

\begin{tabular}{lc}
\hline $\mathrm{kV}(\mathrm{rpm} / \mathrm{v})$ & 7000 \\
\hline Weight $(\mathrm{g})$ & 3.1 \\
Max current (A) & 4 \\
Resistance (mH) & 0 \\
Max voltage (V) & 4 \\
LiPo range & $1 \mathrm{~S} 3.7 \mathrm{~V}$ \\
Voltage (V) (recommended) & 3.7 \\
Current (A) (recommended) & 2.1 \\
\hline
\end{tabular}

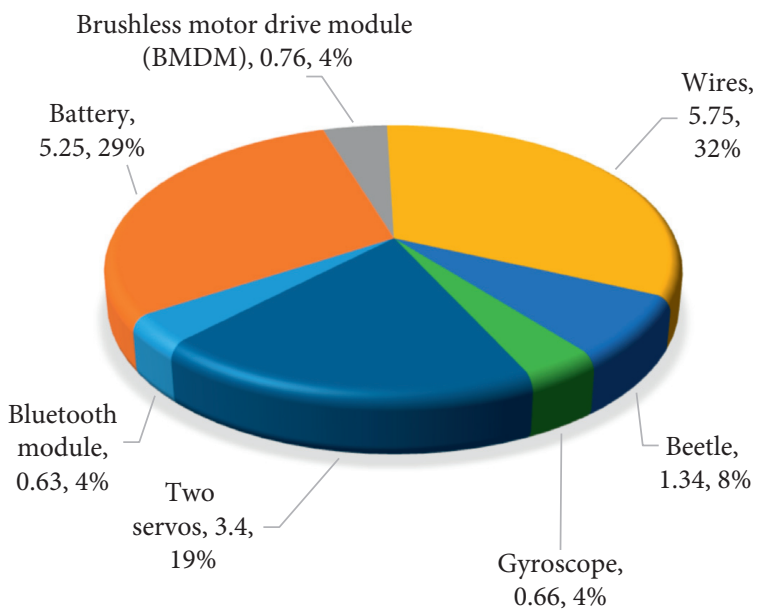

Figure 10: The weight of every part. The total weight is $17.79 \mathrm{~g}$.

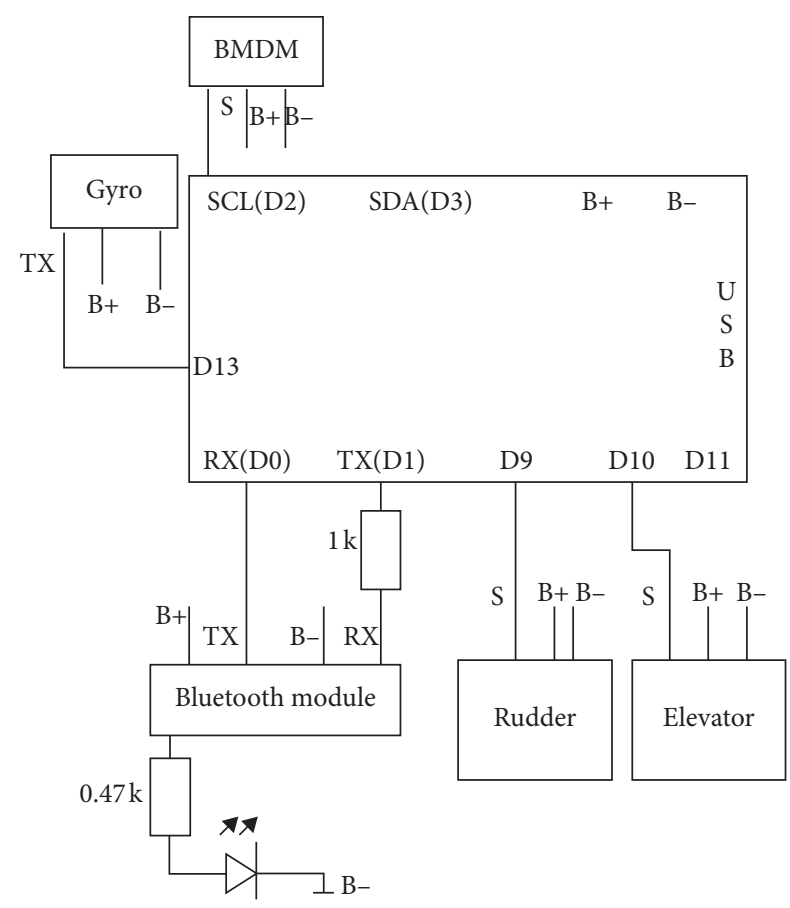

Figure 11: Hardware circuit connection diagram.

communication subprogram, posture control subprogram, and execution subprogram. The control block diagram is shown in Figure 13.
(1) Initialization Subprogram. The initialization module includes the initialization of the corresponding GPIO port and the initialization of the Bluetooth serial communication (setting the Bluetooth pairing and the communication baud rate of 115200).

(2) Wireless Communication Subprogram. This module can determine the order and position of the communication instructions, according to the keyword section of the wireless communication. Then, it can extract the corresponding control instructions (flying speed, forward, left, and right steering) and check the last digit to ensure the accuracy of the communication.

(3) Posture Control Subprogram. This module can read the information of the gyroscope to get the current posture of the ornithopter and compare it with the target flight posture received from the remote controller. Based on the PID control algorithm, it can control the action of servos to adjust the flight posture.

(4) Execution Subprogram. This module can receive the control instructions obtained by the control algorithm and convert them into corresponding PWM signals to control the actions of the brushless motor and servos to complete the execution of the actions.

\section{Flapping-Wing Drone Experimental Verification}

To verify the structural performance and flight control effect of the designed flapping-wing drone, two flappingwing drone prototypes were produced. One has a T-shaped tail fin as shown in Figure 14 and is only controlled manually. Another is controlled by PID strategy and has a cross-directional tail fin as shown in Figure 12. They both performed a vertical flight test as shown in Figures 15 and 16 to simulate the hummingbirds' hovering as shown in Figure 1.

In supplemental files, T-shape Tail Flight Test.mp4 is the flight test video of T-shaped tail fin, and Cross Tail Fly FromTable.mp4 is the flight test video of cross-shaped tail fin.

It can be seen that the ornithopter without control has a larger swing angle than the ornithopter with control. The ornithopter without control has also more lateral displacement and less hovering time. The hovering time of the ornithopter without control is $6.9 \mathrm{~s}$ and the hovering time with control is $15 \mathrm{~s}$. Moreover, there is a more obvious spin flight in the T-shaped flapping-wing drone. This is completely consistent with the previous analysis.

It can be seen from Figures 16-18 that the ornithopter with a control system can hover frequently in a fixed area. Figure 19 shows the angle between the body frame and plumb line. The change frequency of the angle of the crossshaped tail is higher than that of the T-shaped tail, and the amplitude is smaller than that of the T-shaped tail. This indicates that the improved PID strategy can adjust timely the ornithopter posture to hold hovering. 


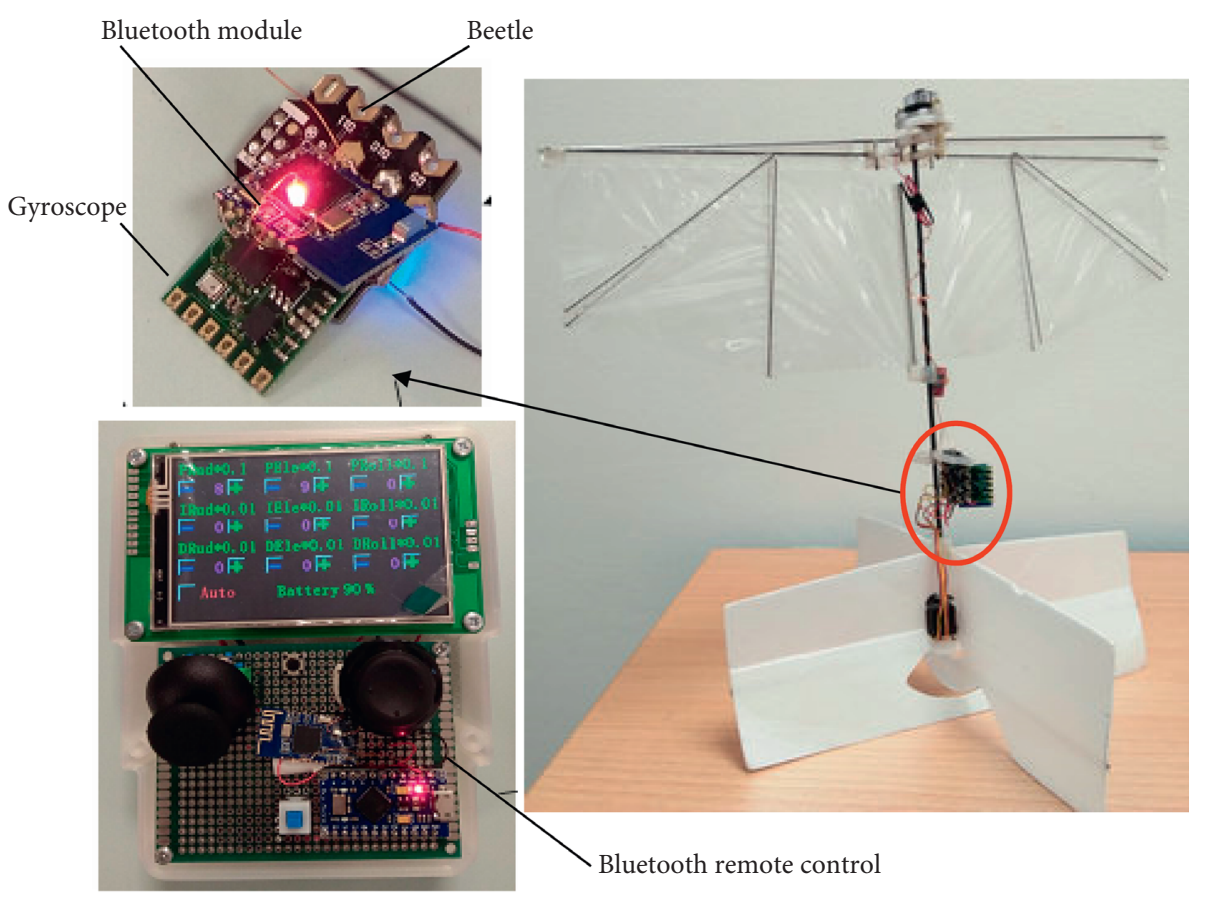

FIGURE 12: The ornithopter, control system, and remote control prototype.

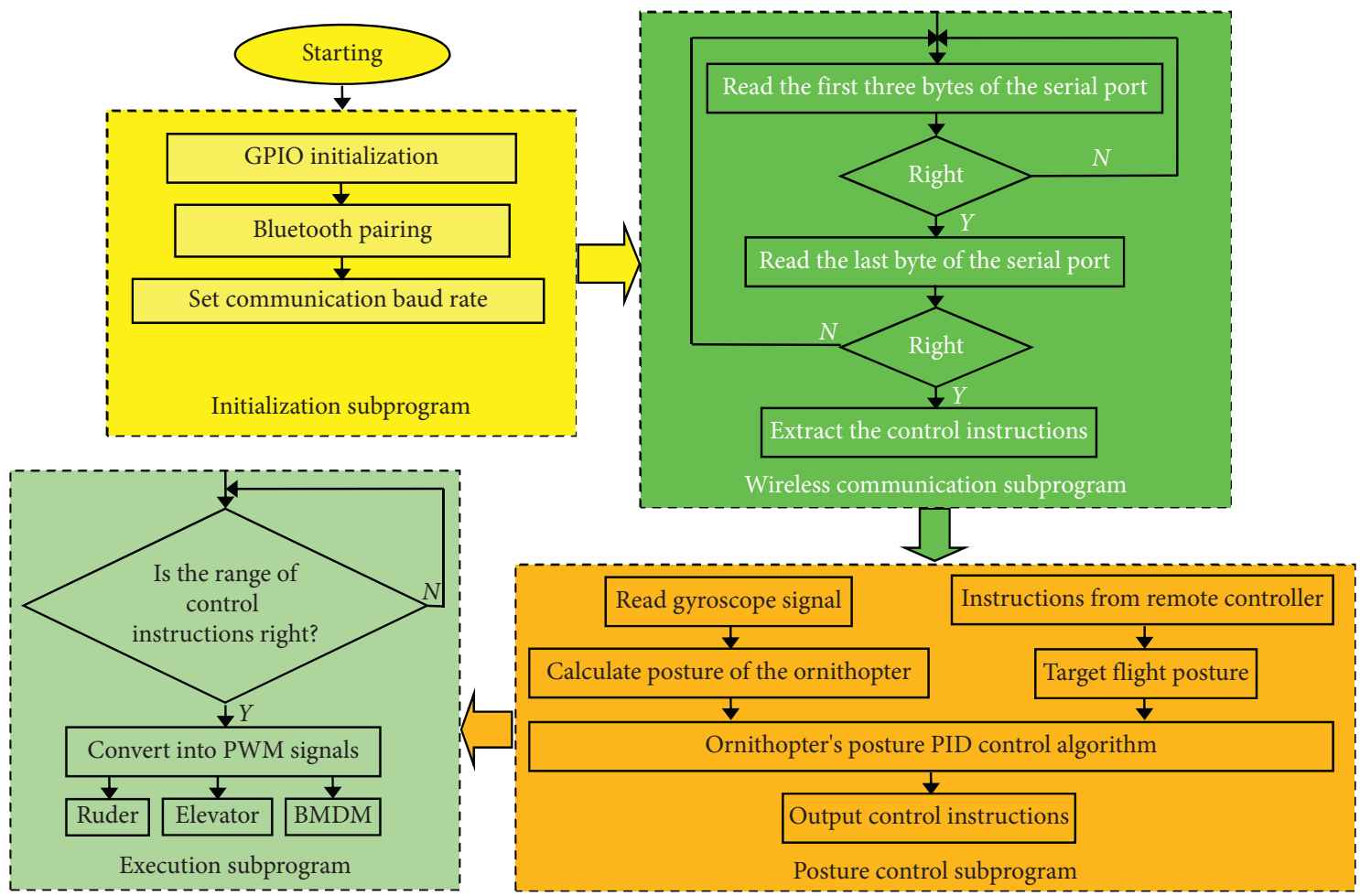

FIGURE 13: The ornithopter control block diagram.

Since the spin flight or yaw in the T-shaped flappingwing drone is more obvious than that of the cross-shaped one. Moreover, the improved PID strategy can only adjust the ornithopter pitch and roll to hold hovering and does not control yaw. So, the cross-shaped tail fin is better than the $\mathrm{T}$-shaped one from the perspective of spin flight.
They also indicate that the designed remote control system and flight control system can achieve a better flight effect in ornithopter's pitch and roll.

At the same time, the flapping-wing drone has a large upward flight acceleration, which proves that the developed flapping-wing drone has a large lift-mass ratio. And 


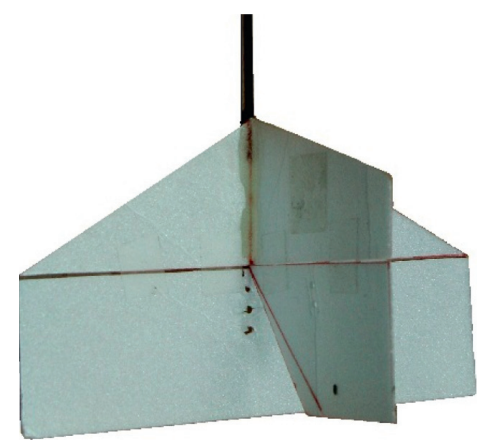

Figure 14: A T-shaped tail fin.

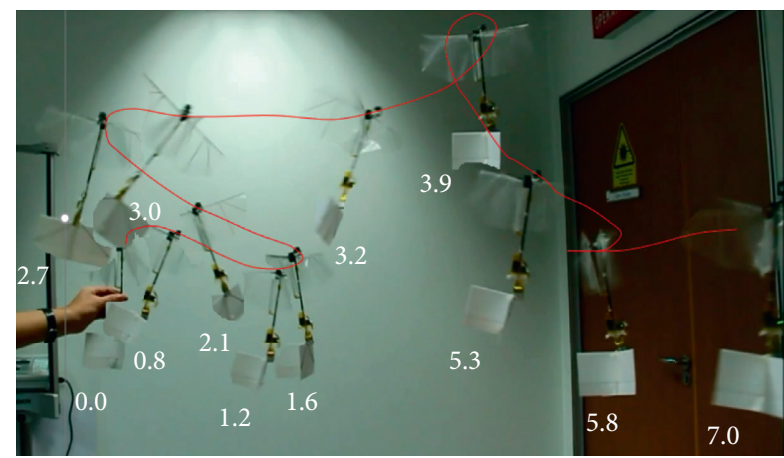

FIGURE 15: T-shaped tail fin flapping-wing flight without control.

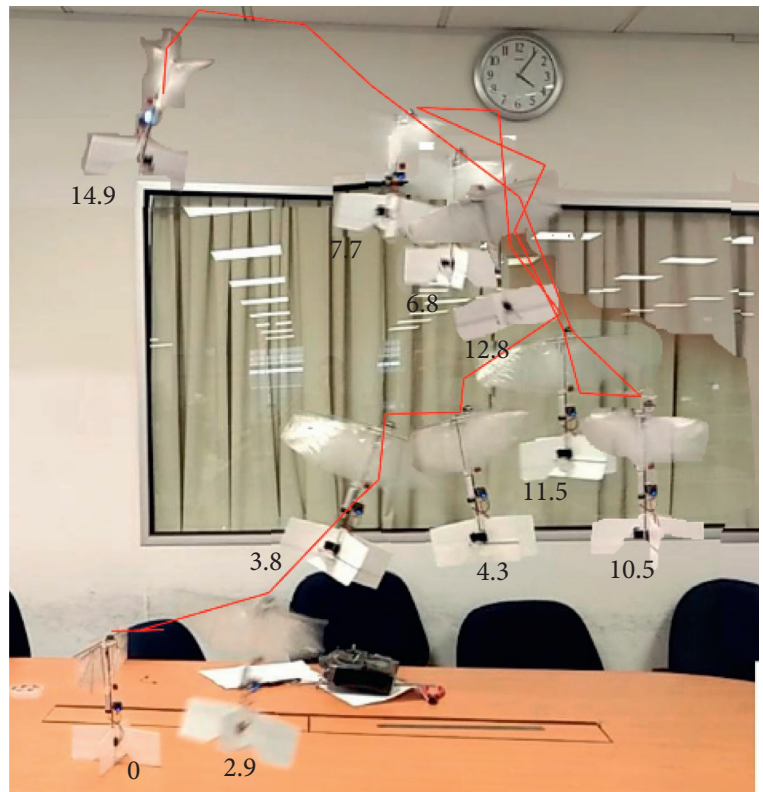

FIGURE 16: Cross-shaped tail fin flapping-wing flight with control.

flapping-wing drone can simulate hummingbirds to achieve a certain hover flight.

However, it can be seen from Figures 17-19 that the tail also sways, and there is a little spin flight in the flappingwing drone. Therefore, further measures need to be taken to ensure a well controllable flight.

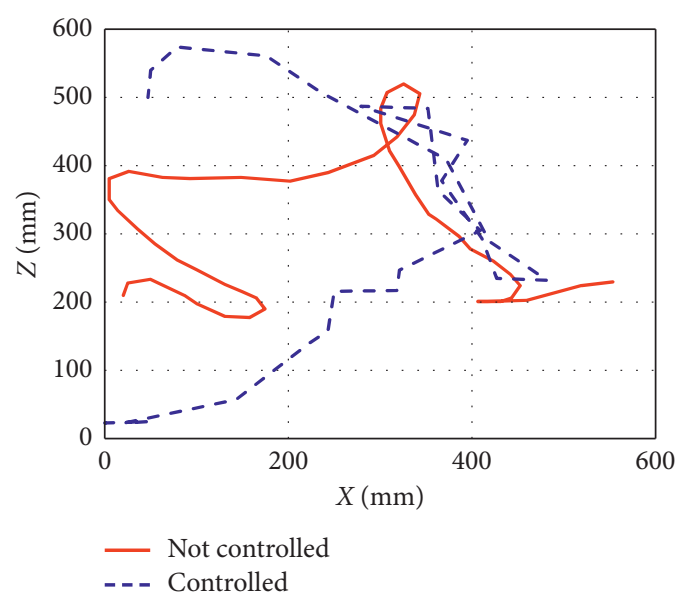

FiguRE 17: Flight trajectory of two flapping-wing drones.

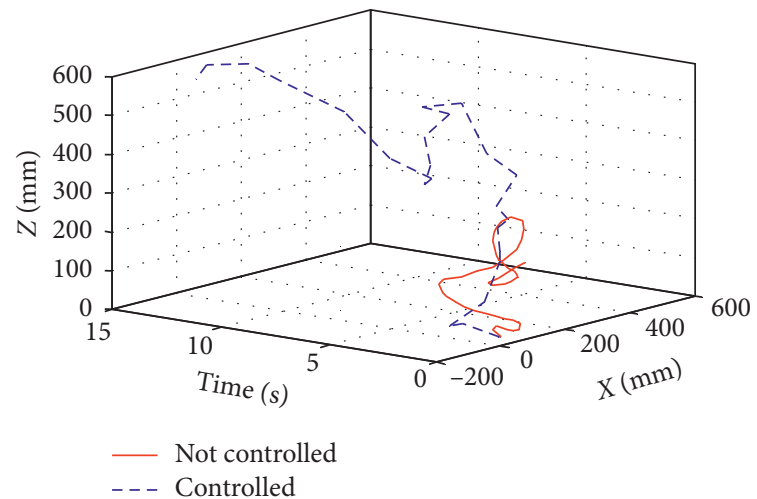

FIGURE 18: Flight trajectory of two flapping-wing drones along time.

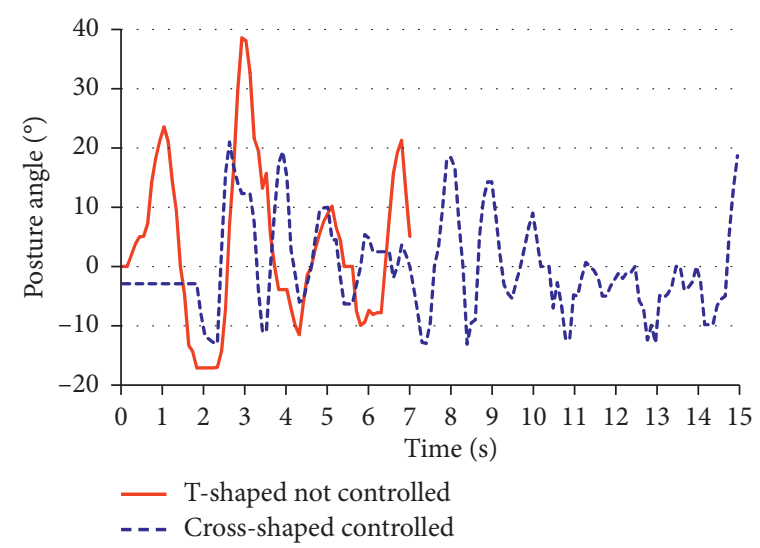

Figure 19: Posture angle curve of flight posture.

\section{Conclusions}

In this research, a new X-shaped flapping-wing drone was proposed, and the specific mechanism of each part of the flapping-wing drone was designed and analyzed. The control mechanism of T-shaped and cross-shaped tail fin of flapping 
wing was analyzed. At the same time, to realize the controllable flight of the flapping-wing drone, a corresponding remote control and flight control system was developed. The hardware circuit and control algorithm were compiled, and two actual flapping-wing drones were produced, and flight experiments were carried out.

The experimental results show that the designed flapping-wing drone has a large lift-mass ratio and good maneuverability. The developed control system and control method can realize the controllable flight of flapping-wing drone and lay the foundation for future research. The crossshaped tail fin is better than the T-shaped tail fin in yawcontrolling performance. The cross-shaped tail fin has a better controllable hovering performance than the T-shape tail fin.

In the next stage, this study will focus on the spin flight and flight stability of the flapping-wing drone and further correct it through structural improvements and algorithm improvements to achieve good flapping-wing flight control.

\section{Data Availability}

The data used to support the findings of this study are available from the corresponding author upon request.

\section{Conflicts of Interest}

The authors declare that they have no conflicts of interest regarding the publication of this paper.

\section{Acknowledgments}

This work was supported by the National Natural Science Foundation of China (no. 51005128), 2018 Teaching Research and Teaching Reform Project of Qingdao University of Technology (no. F2018-113), and 2019 Teaching Research and Teaching Reform Project of Qingdao University of Technology (no. F2019-056).

\section{Supplementary Materials}

T-shape Tail Flight Test.mp4 is the flight test video of T-shaped tail fin. In this video, the flapping-wing drone has a T-shaped tail fin and is only controlled manually. Cross Tail Fly FromTable.mp4 is the flight test video of the cross-shaped tail fin. The flapping-wing drone is controlled by PID strategy and has a cross-directional tail fin. Both flapping-wing drones are the same except the tail fin. (Supplementary Materials)

\section{References}

[1] E. W. Hawkes and D. Lentink, "Fruit fly scale robots can hover longer with flapping wings than with spinning wings," Journal of The Royal Society Interface, vol. 13, pp. 1-6, 2016.

[2] C. Kang and W. Shyy, "Analytical model for instantaneous lift and shape deformation of an insect-scale flapping wing in hover," Journal of the Royal Society Interface, vol. 11, pp. 1-10, 2014.

[3] Y. Nan, K. Matěj, L. Mohamed Esseghir, and P. André, "Experimental optimization of wing shape for a hummingbird-like flapping wing micro air vehicle," Bioinspiration \& Biomimetics, vol. 12, 2017.

[4] S. Chen, H. Li, S. Guo, M. Tong, and B. Ji, "Unsteady aerodynamic model of flexible flapping wing," Aerospace Science and Technology, vol. 80, pp. 354-367, 2018.

[5] P. Deshpande and A. Modani, "Experimental investigation of fluid-structure interaction in a bird-like flapping wing," Journal of Fluids and Structures, vol. 91, p. 102712, 2019.

[6] L. Wang and F.-B. Tian, "Numerical study of flexible flapping wings with an immersed boundary method: fluid-structureacoustics interaction," Journal of Fluids and Structures, vol. 90, pp. 396-409, 2019.

[7] S. Deng, J. Wang, and H. Liu, "Experimental study of a bioinspired flapping wing MAV by means of force and PIV measurements," Aerospace Science and Technology, vol. 94, p. 105382, 2019.

[8] J. Zhu and J. Zhang, "Power extraction performance of two semi-active flapping airfoils at biplane configuration," Journal of Mechanical Science and Technology, vol. 34, no. 1, pp. 175-187, 2020.

[9] K. Stowers Amanda and L. David, "Folding in and out: passive morphing in flapping wings," Bioinspiration \& Biomimetics, vol. 10, 2015.

[10] D. Faux, O. Thomas, S. Grondel, and É. Cattan, "Dynamic simulation and optimization of artificial insect-sized flapping wings for a bioinspired kinematics using a two resonant vibration modes combination," Journal of Sound and Vibration, vol. 460, p. 114883, 2019.

[11] M. Huang, "Optimization of flapping wing mechanism of bionic eagle," Proceedings of the Institution of Mechanical Engineers, vol. 33, pp. 3261-3272, 2019.

[12] M. Hassanalian and A. Abdelkefi, "Towards improved hybrid actuation mechanisms for flapping wing micro air vehicles: analytical and experimental investigations," Drones, vol. 3, no. 3, p. 73, 2019.

[13] C. Chen and T. Zhang, "A review of design and fabrication of the bionic flapping wing micro air vehicles," Micromachines, vol. 10, pp. 1-20, 2019.

[14] M. Keennon, K. Klingebiel, and H. Won, "Development of the nano hummingbird: a tailless flapping wing micro air vehicle," in Proceedings of the 50th AIAA Aerospace Sciences Meeting, p. 588, Simi Valley, CA, USA, January 2012.

[15] Q. V. Nguyen, H. C. Park, N. S. Goo, and D. Byun, "Characteristics of a beetle's free flight and a flapping-wing system that mimics beetle flight," Journal of Bionic Engineering, vol. 7, no. 1, pp. 77-86, 2010.

[16] N. Gaissert, R. Mugrauer, G. Mugrauer, A. Jebens, K. Jebens, and E. M. Knubben, "Inventing a micro aerial vehicle inspired by the mechanics of dragonfly flight," in Towards Autonomous Robotic Systems, pp. 90-100, Springer, Berlin, Germany, 2013.

[17] G. Gremillion, P. Samuel, and J. S. Humbert, "Yaw feedback control of a bio-inspired flapping wing vehicle," in Micro-and Nanotechnology Sensors, Systems, and Applications IV, International Society for Optics and Photonics, Bellingham, WA, USA, 2012.

[18] D. Coleman, M. Benedict, V. Hrishikeshavan, and I. Chopra, "Design, development and flight-testing of a robotic hummingbird," in Proceedings of the 71st Annual Forum of the American Helicopter Society, Virginia Beach, VA, USA, May 2015.

[19] H. V. Phan, S. Aurecianus, T. Kang, and H. C. Park, "Attitude control mechanism in an insect-like tailless two-winged flying robot by simultaneous modulation of stroke plane and wing twist," in Proceedings of the International Micro Air Vehicle 
Conference and Competition, Melbourne, Australia, September 2018.

[20] A. Roshanbin, H. Altartouri, M. Karásek, and A. Preumont, "COLIBRI: a hovering flapping twin-wing robot," International Journal of Micro Air Vehicles, vol. 9, no. 4, pp. 270-282, 2017.

[21] J. Zhang, F. Fei, Z. Tu, and X. Deng, "Design optimization and system integration of robotic hummingbird," in Proceedings of the 2017 IEEE International Conference on Robotics and Automation (ICRA), pp. 5422-5428, 10 Bayfront Avenue, Sigapore, June 2017.

[22] C. De Wagter, M. Karásek, and G. de Croon, "Quad-thopter: tailless flapping wing robot with four pairs of wings," International Journal of Micro Air Vehicles, vol. 10, no. 3, pp. 244-253, 2018.

[23] Q. V. Nguyen and W. L. Chan, "Development and flight performance of a biologically-inspired tailless flapping-wing micro air vehicle with wing stroke plane modulation," Bioinspiration \& Biomimetics, vol. 14, 2018.

[24] M. Karásek, F. T. Muijres, C. De Wagter, B. D. W. Remes, and G. C. H. E. de Croon, "A tailless aerial robotic flapper reveals that flies use torque coupling in rapid banked turns," Science, vol. 361, no. 6407, pp. 1089-1094, 2018.

[25] X. Chi, S. Wang, Y. Zhang, X. Wang, and Q. Guo, "A tailless butterfly-type ornithopter with low aspect ratio wings," in Proceedings of the CSAA/IET International Conference on Aircraft Utility Systems, Guiyang, China, June 2018.

[26] M. Keennon and J. Grasmeyer, "Development of two MAVs and vision of the future of MAV design," in Proceedings of the AIAA International Air and Space Symposium and Exposition: The Next 100 Years, p. 2901, Simi Valley, CA, USA, July 2003.

[27] J. H. Park and K.-J. Yoon, "Designing a biomimetic ornithopter capable of sustained and controlled flight," Journal of Bionic Engineering, vol. 5, no. 1, pp. 39-47, 2008.

[28] C. De Wagter, S. Tijmons, B. D. Remes, and G. C. de Croon, "Autonomous flight of a 20- gram flapping wing mav with a 4gram onboard stereo vision system," in Proceedings of the 2014 IEEE International Conference on Robotics and Automation, pp. 4982-4987, Hong Kong, China, May 2014.

[29] W. Send, M. Fischer, K. Jebens, R. Mugrauer, A. Nagarathinam, and F. Scharstein, "Artificial hinged-wing bird with active torsion and partially linear kinematics," in Proceeding of 28th Congress of the International Council of the Aeronautical Sciences, Brisbane, Australia, September 2012.

[30] A. E. Holness, H. A. Bruck, and S. K. Gupta, "Characterizing and modeling the enhancement of lift and payload capacity resulting from thrust augmentation in a propeller-assisted flapping wing air vehicle," International Journal of Micro Air Vehicles, vol. 10, no. 1, pp. 50-69, 2018.

[31] C. Rose and R. S. Fearing, "Comparison of ornithopter wind tunnel force measurements with free flight," in Proceeding of the 2014 IEEE International Conference on Robotics and Automation, pp. 1816-1821, Hong Kong, China, June 2014.

[32] G. A. Folkertsma, W. Straatman, N. Nijenhuis, C. H. Venner, and S. Stramigioli, "Robird: a robotic bird of prey," IEEE Robotics \& Automation Magazine, vol. 24, no. 3, pp. 22-29, 2017.

[33] M. H. Rosen, G. le Pivain, R. Sahai, N. T. Jafferis, and R. J. Wood, "Development of a $3.2 \mathrm{~g}$ untethered flapping-wing platform for flight energetics and control experiments," in Proceedings of the 2016 IEEE International Conference on Robotics and Automation, pp. 3227-3233, Stockholm, Sweden, May 2016.
[34] M. Ghommem, M. Hassanalian, M. Al-Marzooqi, G. Throneberry, and A. Abdelkefi, "Sizing process, aerodynamic analysis, and experimental assessment of a biplane flapping wing nano air vehicle," Proceedings of the Institution of Mechanical Engineers, Part G: Journal of Aerospace Engineering, vol. 233, no. 15, pp. 5618-5636, 2019.

[35] M. Hassanalian and A. Abdelkefi, "Classifications, applications, and design challenges of drones: a review," Progress in Aerospace Sciences, vol. 91, pp. 99-131, 2017.

[36] A. Shahzad, F.-B. Tian, J. Young, J. C. S. Lai, and S. Lai, "Effects of flexibility on the hovering performance of flapping wings with different shapes and aspect ratios," Journal of Fluids and Structures, vol. 81, pp. 69-96, 2018.

[37] T. Nakata and H. Liu, "Aerodynamic performance of a hovering hawkmoth with flexible wings: a computational approach," Proceedings of the Royal Society B: Biological Sciences, vol. 279, pp. 722-731, 2012.

[38] H. Vu Phan, T. K. L. Au, and H. C. Park, "Clap-and-ling mechanism in a hovering insect-like two-winged lappingwing micro air vehicle," Royal Society Open Science, vol. 3, pp. 160746-162016, 2016.

[39] B. Singh, M. Ramasamy, I. Chopra, and J. Leishman, "Experimental studies on insect-based flapping wings for micro hovering air vehicles," in Proceedings of the 46th AIAA/ASME/ ASCE/AHS/ASC Structures, Structural Dynamics and Materials Conference, p. 2293, College Park, MD, USA, April 2005.

[40] K. Mazaheri and A. Ebrahimi, "Experimental investigation of the effect of chordwise flexibility on the aerodynamics of flapping wings in hovering flight flexibility on the aerodynamics of flapping wings in hovering flight," Journal of Fluids and Structures, vol. 26, no. 4, pp. 544-558, 2010.

[41] K. De Clercq, R. De Kat, B. Remes et al., "Flow Visualization and Force Measurements on a Hovering Flapping-Wing MAV "DelFly II"” in Proceedings of the 39th AIAA Fluid Dynamics Conference, p. 4035, San Antonio, TX, USA, June 2009.

[42] Q. V. Nguyen, W. L. Chan, and M. Debiasi, "Experimental investigation of wing flexibility on force generation of a hovering flapping wing micro air vehicle with double wing clap-and-fling effects," International Journal of Micro Air Vehicles, vol. 9, no. 3, pp. 187-197, 2017.

[43] T. Jiang, X. Yang, H. Wang, W. Gai, and L. Cui, "Longitudinal modeling and control of tailed flapping-wings micro air vehicles near hovering," Journal of Robotics, vol. 2019, Article ID 9341012, 12 pages, 2019.

[44] H. E. Taha, S. Tahmasian, C. A. Woolsey, A. H. Nayfeh, and M. R. Hajj, "The need for higher-order averaging in the stability analysis of hovering, flapping-wing flight," Bioinspiration \& Biomimetics, vol. 10, 2015.

[45] B. Cheng and X. Deng, "Translational and rotational damping of flapping flight and its dynamics and stability at hovering," IEEE Transactions on Robotics, vol. 27, no. 5, pp. 849-864, 2011.

[46] P. Chirarattananon, K. Y. Ma, and R. J. Wood, "Adaptive control of a millimeter-scale flapping-wing robot," Bioinspiration \& Biomimetics, vol. 9, pp. 1-15, 2014.

[47] H. Altartouri, A. Roshanbin, G. Andreolli et al., "Passive stability enhancement with sails of a hovering flapping twinwing robot," International Journal of Micro Air Vehicles, vol. 11, pp. 1-9, 2019.

[48] S. C. Taylor, S. Ferrari, S. B. Fuller, and R. J. Wood, "Spiking Neural Network (SNN) control of a flapping insect-scale robot," in Proceedings of the IEEE 55th Conference on Decision 
and Control, pp. 3381-3388, Las Vegas, NV, USA, December 2016.

[49] E. B. James, C.-K. Kang, and Y. Shtessel, "Control of a flapping-wing micro air vehicle, sliding-mode approach," Journal of Guidance, Control, and Dynamics, vol. 41, pp. 1223-1226, 2018.

[50] J. E. Bluman, C.-K. Kang, and Y. B. Shtessel, "Sliding mode control of a biomimetic flapping wing micro air vehicle in hover," in Proceedings of the AIAA Atmospheric Flight Mechanics Conference, p. 1633, Grapevine, TX, USA, January 2017.

[51] Pérez-Arancibia, O. Néstor, J. P. Whitney, and R. J. Wood, "Lift force control of flapping-wing microrobots using adaptive feedforward schemes," IEEE/ASME Transactions on Mechatronics, vol. 18, pp. 155-168, 2013.

[52] S. Mishra, B. Tripathi, S. Garg, A. Kumar, and P. Kumar, "Design and development of a bio-inspired flapping wing type micro air vehicle," Procedia Materials Science, vol. 10, pp. 519-526, 2015.

[53] Y. Peng, J. Cao, L. Liu, and H. Yu, "A piezo-driven flapping wing mechanism for micro air vehicles," Microsystem Technologies, vol. 23, no. 4, pp. 967-973, 2017.

[54] S. Yoon, L.-H. Kang, and S. Jo, "Development of air vehicle with active flapping and twisting of wing," Journal of Bionic Engineering, vol. 8, no. 1, pp. 1-9, 2011.

[55] P. S. Sreetharan and R. J. Wood, "Passive torque regulation in an underactuated flapping wing robotic insect," Autonomous Robots, vol. 31, no. 2-3, pp. 225-234, 2011.

[56] B. H. Cheaw, H. W. Ho, and E. Abu Bakar, "Wing design, fabrication, and analysis for an X-wing flapping-wing micro air vehicle," Drones, vol. 3, no. 3, p. 65, 2019.

[57] M. Karasek, Robotic hummingbird: design of a control mechanism for a hovering flapping wing micro air vehicle, Ph.D. thesis, Universite Libre de Bruxelles, Bruxelles, Belgium, 2014.

[58] W. Su and C. Cesnik, "Flight dynamic stability of a flapping wing micro air vehicle in hover," in Proceedings of the 52nd AIAA/ASME/ASCE/AHS/ASC Structures, Structural Dynamics and Materials Conference, vol. 13, Ann Arbor, MI, USA, April 2011.

[59] H. E. Taha, M. R. Hajj, and A. H. Nayfeh, "Wing kinematics optimization for hovering micro air vehicles using calculus of variation," Journal of Aircraft, vol. 50, no. 2, pp. 610-614, 2013.

[60] M. Karásek, A. Hua, Y. Nan, M. Lalami, and A. Preumont, "Pitch and roll control mechanism for a hovering flapping wing MAV," International Journal of Micro Air Vehicles, vol. 6, no. 4, pp. 253-264, 2014.

[61] P. E. J. Duhamel, C. O. Perez-Arancibia, G. L. Barrows, and R. J. Wood, "Biologically inspired optical-flow sensing for altitude control of flapping-wing microrobots," IEEE/ASME Transactions on Mechatronics, vol. 18, pp. 556-568, 2013.

[62] C. Badrya, B. Govindarajan, J. D. Baeder, A. Harrington, and C. M. Kroninger, "Computational and experimental investigation of a flapping-wing micro air vehicle in hover," Journal of Aircraft, vol. 56, no. 4, pp. 1610-1625, 2019. 